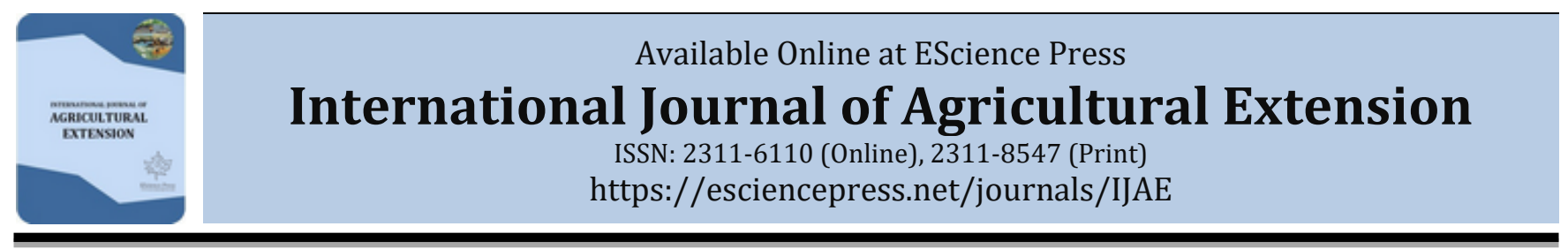

\title{
CHALLENGES IN THE ADOPTION OF IMPROVED ARABLE TECHNOLOGIES AND POSSIBLE SOLUTIONS: A PERSPECTIVE OF FARMERS IN THE SOUTHERN DISTRICT OF BOTSWANA
}

\author{
Moremedi Gagoitsiwe, Hulela Keba* \\ Botswana University of Agriculture and Natural Resources, Faculty of Agribusiness, Education and Extension.
}

*Corresponding Author Email: khulela@buan.ac.bw

A B S T RA C T

This phenomenological study explored the experiences and perceptions of arable farmers in the Southern District of Botswana who have adopted improved technology in arable farming. The purpose of the study was to explore and document the experiences of farmers involved with the occurrence of technology adoption in arable farming in Botswana. A purposive selection of 16 farmers was used to identify participants for this study. Five villages which form the Southern District participated in the study. Data collected through face to face interviews recorded on audio tapes were transcribed coupled with observational field note. The face-to-face interviews were used to gather data analysed using spiral processes, concept mapping as well as thematic areas. Six predominant themes came out clearly to describe areas posing challenges that included education and training for both farmers and extension workers, climate and environmental issues, formation of farmers' clubs and associations, economics and policy issues, and psychosocial issues. Four possible solutions were suggested to consider strengthening and supporting farmers' organizations, increasing producer prices, providing extension workers with practical farming skills and improve farmers' access to credit. A quantitative study would add value as it would compare the results of this study.

Keywords: Arable farming, improved technology, technology adoption, challenges.

\section{INTRODUCTION}

Botswana is an agricultural oriented country concentrating on growing field crops and livestock rearing as the main sub-sectors of the agriculture industry (United Nations Environment Programme, 2011). The agriculture sector/ industry plays a major role and is the backbone of the country's economy for rural and village dwellers (Darkoh \& Mbaiwa, 2002). Currently the sector contributes less than three percent to the Gross Domestic Products (GDP) compared to a proportion of more than forty percent $(\geq 40 \%)$ it contributed in 1966 when the country gained independence from Britain (United Nations Environment Programme, 2012). According to Food and Agriculture Organization of the United Nations (FAO, 2011); FAO, 2005 and Seleka (1999), although thecountry generally performed well soon after independence, the agricultural sector's performance has been underprivileged, as it recorded low if not stationary in terms of growth in output and productivity since 1966. This is also alluded to by Campbell, Main and Hitchcock (2006) in the assessment of strategies placed for the agriculture sector after 1966.

Despite the minimal contribution, the agriculture sector is making to the Botswana's GDP the industry still remains the mainstay of the country's economic development in rural areas as majority of the people including those working in urban areas have their homes and farm fields as well as cattle ranches and cattle posts in rural areas. Similarly, the story is also confirmed by Mmegi (2018) describing the vital role played by agriculture and its nature for the neighbouring Namibia. This is the traditional farming which is dominating the sector as majority of the people still practice agriculture to feed their families.

Sequel to 1966, the government of Botswana found it fit to enhance the agriculture sector through new programs, policies and other strategies which were set 
up in support of farmers through the Ministry of Agricultural Development and Food Security. These were efforts to enhance agriculture development to inspire the spirit whereby farming is seen as a business in addressing food security changing from the traditional system. The goals of the initiatives introduced soon after 1966 have shaped the adoption and advancement of technology not only in Botswana but worldwide (FAO, 2014)

According to UNDP (2011) challenges do exist in the agriculture sector which include inadequate production, infrastructure and support services that hamper production as a result of a numeral systemic gaps. The policy brief as presented by UNDP (2011), further pointed out to the fact that several of the farm fields were also scattered apart making it problematic to provide services such as roads, electricity, water, telecommunications and extension services. According to the brief, the crop production sector of the agriculture industry is heavily affected by challenges than other agricultural entities as crops depends frequently on natural rainfall which may be unpredictable.

The adoption of improved technologies by farmers is one of the perspectives perceived by the government of Botswana to enhance the agriculture sector for the purpose of increasing food production and security. Several technologies have been introduced since independence such as the use of improved breeds of livestock through artificial insemination and other means, new crop varieties and animal breeds, adoption of the use of modern machines and technologies for livestock and crop management. In addition, as alluded to by Farrington and Martin (1988) the use of new knowledge generated through scientific research and improved education have also been adopted to enhance aspects of agriculture. It is important also to note that, Botswana is divided into agricultural ecological zones which are called districts. Each district has been earmarked for the production of a particular agriculture crop, livestock or any entity of agriculture. For example, the Southern District, where this study was conducted is earmarked for arable farming growing mainly maize or corn since the country gained independence in 1966. Farmers in this district have adopted several improved technologies but what still remains unknown is, what the challenges farmers experienced in adopting the technologies to enhance food production and security. Evidence is that a study has never been conducted to explore the challenges experienced by farmers who have adopted the new technology. In addition, it is not documented how the challenges experienced by farmers were solved. This study was therefore designed to investigate the challenges experienced by farmers and the possible solutions of the challenges.

Adoption of improved technologies in agriculture in Botswana: In an effort to address agriculture issues the Botswana government has a Ministry responsible for agriculture which also has well established parastatals that support its mandate such as the Botswana Agricultural Marketing Board [BAMB], the Botswana Vaccine institute [BVI], the Botswana Institute for Technology Research and Innovation (BITRI), and Botswana University of agriculture and Natural Resources [BUAN]. Within the Ministry, there is the Department of Agricultural Research [DAR] which includes the agricultural extension services for transferring information to stakeholders through workshops, field visits, agricultural fairs and technology transfer. The media. Technology Transfer [TT] or transfer of technology [TOT] is a concept whereby the new technology or knowledge generated through experiments or research from is transferred through extension agents to the users who may be farmers to boost the farming economies (OECD, 2001).

According to Straub (2009) technology adoption is a 'complex, inherently social, developmental process; individuals construct unique yet malleable perceptions of technology that influence their adoption decisions'. This means for one to adopt technology successfully will require several factors to be addressed including psychological factors.

Purpose and objectives: This paper formed part of the $\mathrm{PhD}$ research study conducted by the principal investigator in the southern District of Botswana. The purpose of the study was to explore farmers' viewpoints on what they experienced to be the challenges in adopting improved technologies in arable farming in the Southern District and how the challenges were dealt with. The paper specifically;

- Identified the primary challenges experienced by farmers in the adoption of improved technologies in arable farming in the district.

- Described the possible solutions to each one of the perceived challenges identified in the adoption of improved technologies.

- Identified factors influencing the adoption of 
improved technologies in arable farming.

- Described the roles played by stakeholders who addressed the challenges of technologies.

\section{METHODOLOGY}

Participants: Sixteen (16) farmer participants out of one hundred farmers in the southern district were interviewed for this study, one woman and fifteen male farmers. The interviewees had adopted improved technologies in arable farming and had acquired $\geq 16$ ha of land and had experienced adoption of improved technologies. The Farmers' personal characteristics extended from experienced to less experienced, and were middle aged to elderly farmers. Participants' education varied from informal through to non-formal education about technology adoption challenges. Participants purposively studied came from the four Sub Districts namely Ngwaketse South Sub District with Mmathethe as the Headquarters, Ngwaketse North Sub District with Kanye as Headquarters, Ngwaketse West Sub District with Jwaneng as the Headquarters and Barolong Sub District with Good hope as the Headquarters. The four Nwaketse areas formed the southern district of Botswana which is one of the two districts actively involved in dry-land arable farming. Participants were volunteers purposively selected without personal incentive gain for participating in the study and were consented.

Researchers: At the time of this investigation, the principal investigator was a doctoral student investigating the factors affecting the adoption of improved technologies in arable farming in the Botswana's Southern District. In addition, the investigation looked at the challenges faced by farmers in adopting technology and the solutions using both quantitative and qualitative methods. The researchers in this study are currently lecturing at university to undergraduate agricultural extension students on technology transfer and adoption of new technologies. The investigators are seasoned agricultural extensionists, agricultural educationists and researchers at the University of Agriculture and Natural Resources (BUAN) in Botswana where they have been involved in teaching, conducting research and outreach programs to enhance the strategies for food security.

Data collection procedures: The face to face interviews were conducted by the investigators at the farmers' respective farms using a questionnaire (Mathers et al., 2009). Semi structured questions as described by
Mathens et al. (2002) were used coupled with follow-up questions to seek for clarity. As guided by the literature from Merriam, (2002) a consent was sought from the participants prior to the interviews. Farmer participants were interviewed at their farms twice at different times when the investigators visited the farms for data collection. The study used the face to face interview techniques to understand the experiences of farmers in their farming environment (Al-Yateem, 2012; Oltmann, 2016). In addition to the face to face interviews, the investigators kept observational journals for enhancement of the responses from the interviews.

Three open ended questions were posed to farmer participants to indicate their views, opinions, experiences and perspectives about the changing experiences in adopting improved technologies in arable farming. The three questions were; i. What fundamental challenges did you experience in adopting improved technologies in arable farming? ii. What do you think needs to be done in order to address the challenges you have experienced? iii. Who do you think would be appropriately placed in ameliorating the changes identified to enhance production in the arable farming sector? For each question, through follow-up questions the farmer participants were asked to elaborate further for the understanding of the interviewees.

Face-to-face interviews: Interviews were tape recorded to ensure accuracy in data capturing and did not exceed 30 minutes with each interviewee, Respondents were asked for investigation's clarity to further elaborate on responses not clearly captured by the researcher. To explore further, farmer participants were asked to add their views which may not have been covered in each of the three questions posed for the investigation. The interviews focused on identifying challenges experienced in arable agriculture in the district, categorizing the challenges, determining how the challenges were addressed, and who addressed the identified challenges in different farms. The personal interviews recorded information and later transcribed verbatim and interpreted to make meaning out of the farmers' experiences with technology adoption challenges.

Personal diaries and journals: The personal diary/ journals of observational entries were made at all visits to support the face to face interviews data. The use of interviews was coupled with observations recorded upon visiting farms to strengthen the quality of 
investigations. As indicated by Honorene (2017) and Carter et al. (2014) that triangulation refers to the practice of using a multiple sources of data and methods to enhance the credibility of the research study. According to Janesick (2007) journals provide a data that make researcher's do some reflections on their experiences and that of the participants being investigated. Furthermore, data gathered through personal interviews have the advantage over mail and telephone surveys in terms of the complexity and quality of the data collected (Doyle, n.d p 1).

Analysis of qualitative data: Making meaning out of the qualitative data was a process by which the researchers started at the time of gathering data from farmers (audio recorded) interpreted, understood or made sense out of the data and shown relationships. The analysis involved different techniques that included content analysis, spiral processes, analysis circles and concept mapping. A concept map technique was used to group the themes that emerged from the data into boxes creating thematic areas (Padilla-Diaz, 2015). According to Daley (2004) a concept map is an important approach in qualitative research because it helps researchers to focus ideas obtained from participants in order to make meaning out of what has been gathered using arrows. Concept map can be used to show relationships, connections and associations of concepts gathered. In qualitative research as indicated by Daley (2004) a concept map plays a major role where it is used to frame or plan research project, reducing data into a meaningful piece of work, analysing themes that emerge from narrative data and also presenting the findings graphically for understanding.

In addition the data collected for this study which included narrative statements was also analysed using a spiral process as described by Creswell (2013) involving reading out the statements several times and making meaning. The spiral process involves coding the data, creating themes and managing the data by returning to the original data to read again several times for understanding. .

\section{RESULTS AND DISCUSSION}

Objective \# 1: Challenges experienced by farmers when adopting improved technologies in arable farming: The sixteen (16) farmers' responses to the face to face personal interviews produced several varied challenges faced by farmers when adopting enhanced technologies. The interviews were complimented by diaries kept by the investigators. Figure 1 shows that forty challenges were identified ranging from those related to resource unavailability such as funding, equipment, infrastructure, implement, consumables to those challenges related to capacity development. The challenges were analysed and categorised into six [6] namely, those related to education and training, climate and environmental issues, technology and infrastructure, economic and policy issues, and those associated with psychosocial issues (Figure 1). According to Patel \& Connolly (2007) several factors do affect the adoption processes such as social issues and characteristics of adopters as they influence behaviours to adopt and not to adopt.

The results in Figure 1 suggest that farmers experience a wide range of challenges cutting across all factors of farming life in adopting improved technologies (Figure 1). In order to make meaning out of the data, the process of analytic circle as described by Sage Publications (2017) was used to analyse data starting with preliminary read-through process, coding data based on similarity of statements followed by creating themes from the data. To ease the interpretations, a concept map was then used to organize the themes in boxes with arrows showing issues that pose to challenges confronted when adopting improved technologies [Figure 1]. The topics in each box show a relationship and connectivity.

According to Straub (2009) the decision of a farmer to adopt or not to adopt a particular technology or innovation as well as the time the farmer takes to make a decision has been under investigations by many scholars worldwide. For example, Melesse (2018) reported three factors that could affect the adoption of technology as institutional based, socio-economic and the demographic issues. In another study, Talukder (2012) found that peers and social network groups also affect the adoption of improved technologies.

According to Maguire \& Delahunt (2017) the thematic analysis is the procedure of finding patterns relationships and connections within the data to get meaning. This method helped to identify areas, meaning and key issues from the data to enable researchers interpret and form theories. The themes identified in this study are in line and match with the conceptual framework as presented by Mellesse (2018) and are discussed as follows;

Education and training: The results show that farmers believe that their education and training as in farming 
are crucial to understand technology they adopt. One farmer responded to the interview by stating that;

We need to be educated about the technology we are adopting' and 'we need skills' and knowledge to use the technology'.

Furthermore, responses gathered showed that we need necessary education about farming, farmers stated. According to Riddell \& Song (2012) some previous studies have indicated that people with education tend to adopt new technologies in a faster way than those with less education.

This implies that education has influence on adoption of improved technologies and helps to increase the probability of using computers in the farms and employees have longer work experiences in using computers than those with less education.

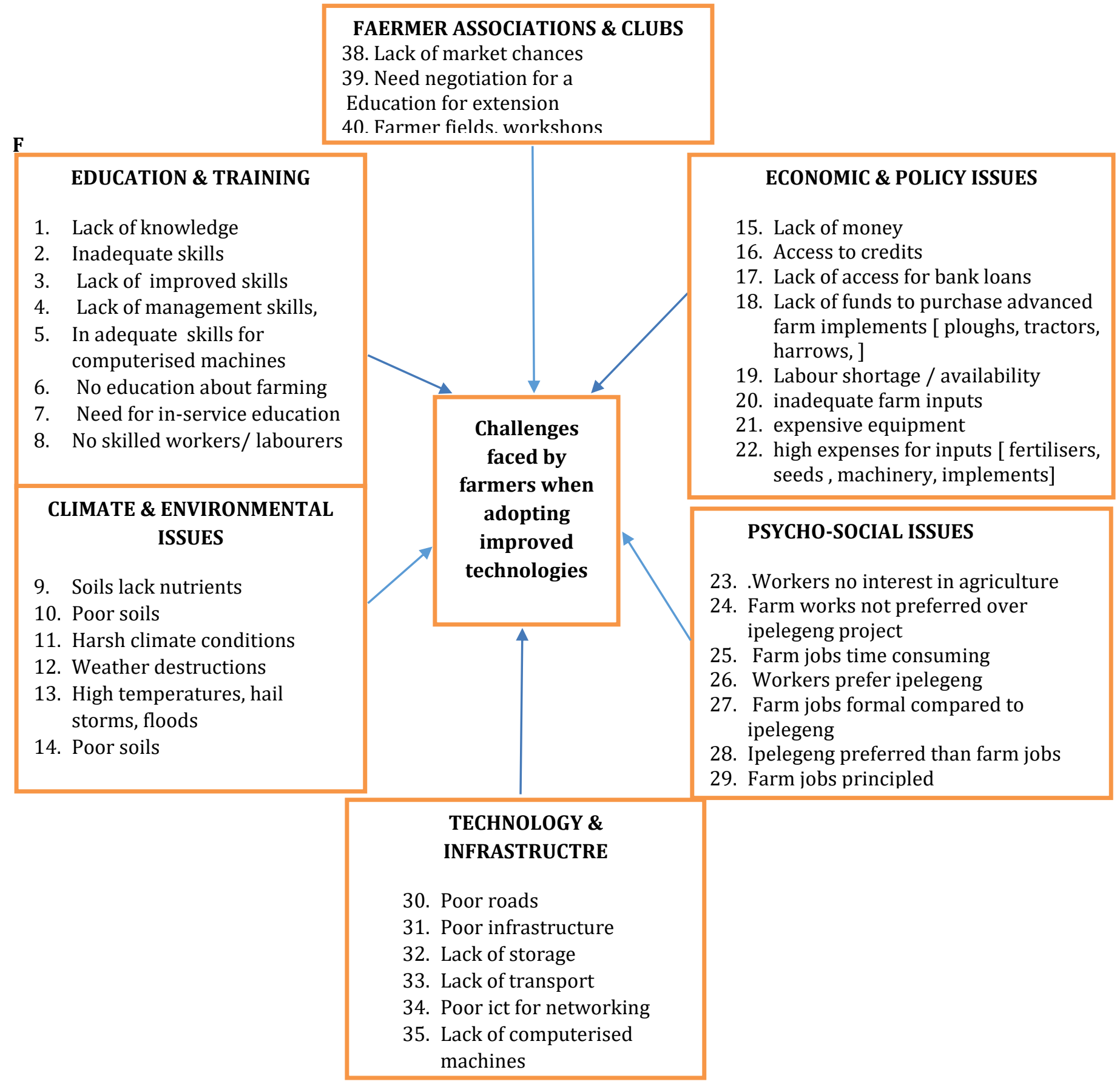

Figure 1. Challenges experienced by farmers in adopting technologies in arable farming.

Source: Analysis from data collected from farmers. 
With regard to extension officers, respondents impressed upon their need for 'education, training and upskilling' of extension workers. Farmers believe that holistic education of extension workers is imperative for the development of agriculture.

Farmer's association and cooperatives: Farmer responses pointed out to the need for farmers associations that will help in grouping farmers for education, negotiations, 'sharing information' and for negotiating marketing strategies and policy development. Participants believe that farmers were better through peer sharing their experiences hence the need for farmer associations and cooperatives specifically for farmers to share their experiences.

Technology and infrastructure: The theme came out clearly from the need for development and construction of needed infrastructure for farmers. They indicated that there was need for roads to reach out to different farms, transport, inputs, produce and networking. Among other things listed are the need for storage facility, research for development in farms by both farmers and extension. The identified challenges corroborates with the findings reported by FAO (2007). This report included that the cold storage and several others posing difficulty in agriculture. Watson (2013) in Zimbabwe found that the unfriendly status of infrastructure does exist and there is need to put more investment on infrastructure development to improve agriculture development. Thus, farmers are demanding improvement in farm fields.

Psychosocial issues: Psychosocial issues raised both psychological and sociological aspects as a challenge as they believe that people working in farms have lost interest, love and the zeal to work in farms because of policies such as those of ipelegeng. This tends to counteract the farm jobs which allow workers to be at work for a longer period. Nthomang (2018) described the ipelegeng philosophy to refer to the spirit of self-help and self-reliance. The practice as raised by farmers has implications for both psychological and sociological issues. The philosophy of ipelegeng encourages workers to work less than 4 hours a day, with less supervision disregarding skills and knowledge hence people tend to spend time there than in farms. Farmers impressed upon negotiating with government for looking into policies that counteract issues of agriculture and food production and security. Thelin \& Doham (2016) reported a number of psychological factors including stress, interest, hours of working as contributing to challenges experienced by farmers in adopting technologies.

Economic and policy issues: Farmers raised a number of issues associated with availability and access to funding organisations and banks as a challenge in farming. It came out undoubtedly that there is a challenge of 'lack of funds' 'labour challenge is a policy issue, 'banks not giving credits to farmers' 'crop produce prices not intensifying while inputs costs are high'. This could be due to risks and uncertainty associated with farming as influenced by climate issues. The low prices for agricultural produce paid by Botswana Agricultural Marketing Board (BAMB) was also raised as a policy that needs to be re-considered. Crop farmers in Botswana sell their produce mainly to the Botswana Agricultural Marketing Board (BAMB) which is a government parastatal.

Climate and environmental issues: Issues raised here are poor soils, soil fertility, and unreliable rainfall, natural disasters such as floods, frost, hail storm, and drought associated with climate change, pests and diseases causing threat to the arable farming that they do in the southern district. Studies have shown that issues of climate change do affect farmers in their applications of improved technologies.

The conclusion drawn from these challenges is that each one is related to one another in one way or the other, that is, the absence and existence of one challenge is seen to affect the other. For example, knowledge about farming helps get access to funding that influences the acquisition of appropriate machinery/ farm equipment to accept and address issues of climate change.

Objective \# 3: Possible Solutions to enhance agricultural technology adoption: Several possible interventions were suggested by farmers for the enhancement of agricultural technology adoption in arable farming that include: Strengthening and supporting farmers' organizations to facilitate learning, increasing producer prices to offset high cost of production, upgrading and up-skilling of extension officers to empower them with practical skills that will ensure training of farmers, and revisiting policies to support agriculture. These proposed interventions are discussed subsequently as follows;

Strengthening and supporting farmers' organizations: The dominant and first solution called for by farmers was the need to revive the idea of associations or club formation by farmers. Majority of 
the farmer participants indicated that farmer associations would assume roles of "advancing concerns of the farming community to authorities, provide fora for farmers to learn from each other, organizing training workshops for its members by inviting experts from various fields, assists its members with crop marketing and ensuring that its members get farm inputs within reach and at reasonable prices'. The farmers' views are consistent with findings of a study conducted by Mwangi \& Kariuki (2015) in Kenya which found that one of the determinants for agricultural technology adoption was through social group. Mwaura (2014) also found that farmers who belong to a particular group are able to adopt improved technologies easily and even achieve higher yields in crop production. The same sentiments were shared by Uwaegbuonu (2010) and Langyintuo \& Mekuria (2008) whose studies found that farmer groups facilitated adoption of improved farming methods and exposed farmers to new technologies as well as stimulating communications respectively.

In the context of Botswana, the Auditor General's Performance Audit Report (2010) for the Department of Crop Production reported that Farmers' Associations/ Committees are established with the objective of promoting socio-economic interests of members to ensure; (i) farmers voice were heard, (ii) promotion of spirit of self- reliance, (iii)cooperation and unity among farmers, (iv) effective contribution to the country's selfsufficiency in food production, (v) shared services to reduce costs of input and machinery and marketing of produce;(vi) collective conservation of agricultural resources such as land and water, and (vii) compete productively with the national and international community.

Increasing producer prices: The intervention suggested as a second solution was to increase producers prices addresses the thematic area of 'economic and policies' which emerged from issues associated with inadequate funds, labour shortage and access to credit loans, Farmer participants voiced out that promoting adoption of technologies can be achieved through increasing producer prices more so that cost of production were escalating. Farmer participants feel that increase in producer prices would conversely increase farm income that would enable farmers to procure required farm inputs, farm machinery and equipment to facilitate implementation or application of the recommended technologies. The participants in this study raised as a concern that the current producer prices offered by Botswana Agricultural Marketing Board (BAMB) are low and serve as a disincentive for technology adoption. It was for this reason that participants argued that there is a need for Government to support BAMB to capacitate it to pay higher producer prices as a policy matter.

\section{Providing extension workers with practical farming} skills: Analysis of data revealed that the third solution was that, participants tend to believe that the extension service is one of the key facilitators for technology adoption. Farmer participants observed that some extension workers lack practical farming skills, hence, the need for providing such extension workers with practical farming skills in line with the thematic area of 'education and training' in Figure 1. This facilitation is generally achieved through training farmers, creating awareness about the existence of appropriate technologies and ensuring that farmers have necessary skills to apply recommended technologies. Participants further stated that some extension workers lack the necessary skill to deal holistically with farming and farmer issues. They further observed that some extension workers tended to emphasize theory at the expense of practice. To this end, some participants indicated that extension workers need to learn practical aspects of farming from them because they (extension workers) are more versed on theoretical aspects of farming while farmers are concerned with practical aspects of farming.

One participant stated that "some extension
workers regard advanced farmers as having a
superior practical understanding of improved
technologies and as a result, they do not feel
comfortable around such farmers". The farmer
further stated that ". . extension workers in our
area, and the only impediment is that at times, we
are not at the same level of understanding of
technologies". They asserted that extension
workers only come to their farms to "collect data
that will enable them to prepare reports and do
not offer any assistance because they seem to lack
practical farming skills".

This results are supported by Auditor General's Report (2010) that testified that the Botswana's department of Crop Production did not offer adequate training to the front line extension workers, especially on a long-term basis, 'in spite of the fact that their duties required them 
to transfer modern farming technologies to farmers' ( $\mathrm{p}$. 27). The report concluded that front line extension workers "had limited capacity in terms of practical skills to provide advisory services, especially for commercial agriculture" (p. 27). This is also observed as stated in the National Development Plan (NDP) 10 which stated that "extension system, which provides advice to farmers, is currently very deficient" (Republic of Botswana, 2009, p. 190). The finding, therefore, adds credence to an already existing body of information on the quality of extension workers and extension delivery system. In addition, the finding contributes to the debate on whether the current crop of extension workers is adequately equipped to assist all categories of farmers.

The implication of the finding is that authorities are generally aware that extension workers, or at least some of them are deficient in practical aspects of farming. Kelsey (2013) attributed low technology adoption rates in Sub-Saharan Africa to poor circumstances created by poorly functioning markets and lower profits that farmers received. Kelsey concluded that farmers received lower profits on account of low producer prices. In the same vein, the Food and Agriculture Organization (2007) observed that paying producer premium prices was one of the key incentives for farmers to adopt modern farming methods.

Improve farmers' access to credit: Fourth, farmers elucidated to the fact that access to credit was an essential ingredient for agricultural technology adoption. Farmer participants agreed that implementation of modern and improved farming methods is costly. There was a consensus drawn from farmers' responses that the costs of farm inputs such as fertilizers, seeds and farm machinery and equipment were high and not easily afforded by farmers. Farmer respondents opined to the fact that improved access to credit enhanced farmers' ability to buy required farm inputs and equipment. Furthermore, credit enabled farmers to offset transport costs associated with transporting inputs from suppliers to the farm and farm produce to the markets. Participants emphasized that majority of farmers cannot afford the required operations without a robust credit line. They reckoned that historically, commercial banks did not target farmers as potential clients and 'farming has not been accorded the same recognition like other business undertakings'. Participants observed that 'majority of farmers who are doing well are those who at some point got financial support to get the right type of farm machinery and equipment and also to buy inputs, especially fertilizer and fuel'. As indicated in the NDP 9, the strategy to facilitate the process of agricultural development was to be achieved through "research, training, extension, the provision of infrastructure and access to credit" (Republic of Botswana, 2003). Research by Mwangi \& Kariuki (2015); Challa \& Tilahun (2014) in Kenya and Ethiopia respectively support the findings.

\section{CONCLUSION AND RECOMMENDATIONS}

This phenomenological study explored the experiences and perceptions of arable farmers in the Southern District of Botswana who have adopted improved technology in arable farming. This study examined farmers' insights of the challenges that they face in the adoption of improved agricultural technologies and at the same time examine what needs to be done to enhance agricultural technology adoption. Based on the results, the study concluded that the agricultural technology adoption is crucial for increasing agricultural productivity, easing poverty, improving farm incomes, and improving standards of living and reducing foodinsecurity among farmers.

The study has revealed that agricultural technology adoption is inhibited by a multiplicity of issues such as low and no education, poor infrastructure in production areas, high cost of farming inputs and lack of labour in farms as well as policies.

The face-to-face interviews were used to gather data and analysed using spiral processes, concept mapping and thematic areas based on content analyses. Six predominant themes came out clearly to describe areas posing challenges that included the need for education and training for both farmers and extension workers, climate and environmental issues, farmer clubs and associations, economics and policy issues, and psychosocial issues.

To escalate and activate the likelihood of adopting improved agricultural technologies by farmers, policy makers should put in place all the necessary infrastructural developments in production areas and possibly halt or re-schedule interventions such as Ipelegeng in Setswana which is translated to mean selfhelp or self-reliance" that appear to compete with farmers for farm labourers. Though farmers understand and are generally aware of some improved agricultural technologies, they still faced application distractions, hence a need for policy makers and relevant 
stakeholders to improve farmers' access to credit, capacitate extension workers with practical farming skills and improve producer prizes to compensate for escalating cost of production.

\section{REFERENCES}

Al-Yateem, N. (2012). The effect of interview recording on quality of data obtained: a methodological reflection. Nurse Researcher, 19(4), 31-35.

Campbell, A., Main, M., \& Hitchcock, R. K. (2006). Land, livestock, \& labor in rural Botswana: The western sandveld region of Central District as a case study. Senri ethnological studies, 70, 183-228.

Carter, N., Bryant-Lukosius, D., DiCenso, A., Blythe, J., \& Neville, A. J. (2014). The use of triangulation in qualitative research. In Oncology nursing forum (Vol. 41, No. 5).

Challa, M., \& Tilahun, U. (2014). Determinants and impacts of modern agricultural technology adoption in west Wollega: the case of Gulliso district. Journal of Biology, Agriculture and Healthcare, 4(20), 63-77.

Creswell, J. W. (2013). Qualitative Inquiry \& Research Design: Choosing among Five Approaches (3rd ed.). Thousand Oaks, CA: SAGE.

Daley, B. J. (2004). Using concept maps in qualitative research, Concept Maps: Theory, Methodology, Technology Proc. of the First Int. Conference on Concept Mapping Pamplona, Spain. Available at https://pdfs.semanticscholar.org/814b/ 4b4ac5e27ea8b60194a07e00adfcc0b4007a.pdf.

Darkoh, M. B. K \& Mbaiwa, J. (2002). Globalisation and the Livestock Industry in Botswana. Singapore Journal of Tropical Geography, 23(2),149-166.

Doyle, J. K. (2014). Face-to-face surveys. Wiley StatsRef: Statistics Reference Online.

FAO, (2005). Irrigation in Africa in figures - AQUASTAT Survey 2005. Botswana. Online available at http://www.fao.org/nr/water/aquastat/countrie s regions/BWA/BWA-CP eng.pdf.

FAO, (2007). Review of the challenges and opportunities for rural infrastructure and agroindustries development in the Asia Pacific Region. http://www.fao.org/3/a-ag128e.pdf

FAO, (2014). Food and Agriculture Organization of the United Nations (FAO) and Government of Botswana Country Programming Framework for Botswana $2014-2016$.

Farrington, J., \& Martin, A. M. (1988). Farmer participatory research: A review of concepts and recent fieldwork. Agricultural Administration and Extension, 29(4), 247-264

Honorene, J. (2017). Understanding the role of triangulation in research. Scholarly Research Journal for Interdisciplinary Studies, 4, 91-95.

Jamshed, S (2014). Qualitative research methodinterviewing and observation. Journal of Basic and clinical pharmacy, 5(4), 87-88.

Janesick, V. J. (1999). A journal about journal writing as a qualitative research technique: History, issues, and reflections. Qualitative inquiry, 5(4), 505-524

Kesley, J.B. (2013). Constraints on the adoption of agricultural technologies in developing countries. Literature review. Agricultural technology initiative. J-PAL (MIT) and CEGA, UC, Berkely

Langyintuo, A. S. \& Mekuria, M, 2008. "Assessing the influence of neighborhood effects on the adoption of improved agricultural technologies in developing agriculture," African Journal of Agricultural and Resource Economics, 2(2), 1-19.

Maguire, M., \& Delahunt, B. (2017). Doing a thematic analysis: A practical, step-by-step guide for learning and teaching scholars. AISHE-J: The All Ireland Journal of Teaching and Learning in Higher Education, 9(3).

Mathers, N., Fox, N \& Hunn, A (2002), Trent Focus for Research and Development in Primary Health Care Using Interviews in a Research Project. Trent focus group using interviews in a research project.

Melesse, B. (2018). A review on factors affecting adoption of agricultural new technologies in Ethiopia. Journal of Agricultural Science and Food Research, 9(3), 1-4.

Merriam, S. B. (2002). Introduction to qualitative research. Qualitative research in practice: Examples for discussion and analysis, Jossey-Bass, 464.

Mwangi, M., \& Kariuki, S. (2015). Factors determining adoption of new agricultural Technology by smallholder farmers in developing countries. Journal of Economics and sustainable development, 6(5), 206-216.

Mwaura, F. (2014). Effect of farmer group membership on agricultural technology adoption and crop productivity, African Crop Science Journal, 22(4), 917-927.

Nthomang, K. (2018). Botswana's Ipelegeng Programme 
Design and Implementation: Reduction or Perpetuation/Entrenchment of Poverty? Asian Journal of Social Science Studies, 3(3), 27-38.

Oltmann, S. (2016). Qualitative interviews: A methodological discussion of the interviewer and respondent contexts. In Forum Qualitative Sozialforschung/Forum: Qualitative Social Research, 17 (2).

Ounsaneha, W., Suksaroj, T. T., \& Chamondusit, K. (2012). Selection of the sustainable area for rubber plantation of Thailand by Eco-efficiency. Procedia-Social and Behavioral Sciences, 40, 5864.

Padilla-Diaz, M. (2015). Phenomenology in educational qualitative research: Philosophy as science or philosophical science? International Journal of Educational Excellence, 1(2), 101-110.

Patel, H., \& Connolly, R. (2007). Factors Influencing Technology Adoption: A Review. In 8th International Business Information Management Conference, Dublin, Ireland. Retrieved February (Vol. 15, p. 2018).

Rahimi, F. (2010), ICT, UL Chapter 3: Research design and methodology. University of Pretoria.98-123.

Republic of Botswana (2016) National Development Plan

10.

https://www.finance.gov.bw/images/NDPTEN/NDP_TEN_final.pdf

Republic of Botswana. (2003). National Development Plan 9. Gaborone: Ministry of Finance and Development Planning.

Republic of Botswana. (2009). National Development Plan 10. Ministry of Finance and Development Planning. Gaborone: Government Printers.

Riddell, W.C., \& X. Song. (2011). The role of education in technology use and adoption: evidence from the
Canadian workplace and employee survey." CLSRN Working Paper 83. Vancouver: Canadian Labour Market and Skills Researcher Network.

Salkind. N. J. (2002). Exploring research fourth edition. Prentice Hall. Upper Saddle River. New Jersey. Prentice Hall.

Seleka T. B. (1999). The performance of Botswana's traditional arable agriculture: growth rates and the impact of the accelerated rain fed arable programme (ARAP). Elsevier Science. Agricultural Economics, (20), 121-133

Straub, E. T. (2009). Understanding Technology Adoption: Theory and Future Directions for Informal Learning. Review of Educational Research, 79(2), 625-649.

Talukde, M. (2012). Factors affecting the adoption of technological innovation by individual employees: An Australian study. Procedia Social and Behavioral Sciences, 40, 52-57.

UNDP, (2011). Agriculture and Food Security Policy Brief Reflecting on the Challenges of Attaining a Green Economy for Botswana. Retrieved on 10/12/2019.

United Nations Environment Programme, (2011). Agriculture and Food Security Policy Brief Reflecting on the Challenges of Attaining a Green Economy for Botswana.

Uwaegbuonu O. I. (2010). Determinants of adoption of new technologies and the role of credit in the production of rice in Benue State, Nigeria, Agricultural Journal, 5(4), 264-268.

Watson, M. (2013). Agricultural infrastructure development imperative for sustainable food production: a Zimbabwean perspective. Russian Journal of Agricultural and Socio-Economic Sciences, 24(12).

Publisher's note: EScience Press remains neutral with regard to jurisdictional claims in published maps and institutional affiliations.

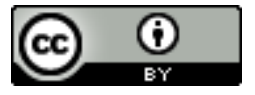

Open Access This article is licensed under a Creative Commons Attribution 4.0 International License, which permits use, sharing, adaptation, distribution and reproduction in any medium or format, as long as you give appropriate credit to the original author(s) and the source, provide a link to the Creative Commons license and indicate if changes were made. The images or other third-party material in this article are included in the article's Creative Commons license, unless indicated otherwise in a credit line to the material. If material is not included in the article's Creative Commons license and your intended use is not permitted by statutory regulation or exceeds the permitted use, you will need to obtain permission directly from the copyright holder. To view a copy of this license, visit http://creativecommons.org/licenses/by/4.0/.

(C) The Author(s) 2019. 